\title{
Dosimetric comparison of incidental axillary irradiation between three-dimensional conformal and volumetric modulated arc techniques for breast cancer
}

\author{
IN YOUNG JO ${ }^{1}$, EUN SEOG KIM ${ }^{1,2}$, WOO CHUL KIM ${ }^{1}$, CHUL KEE MIN $^{1}$ and SEUNG-GU YEO ${ }^{1,2}$ \\ ${ }^{1}$ Department of Radiation Oncology, Soonchunhyang University Hospital; \\ ${ }^{2}$ Department of Radiation Oncology, Soonchunhyang University College of Medicine, \\ Soonchunhyang University Hospital, Cheonan, Chungnam 31151, Republic of Korea
}

Received March 7, 2019; Accepted February 4, 2020

DOI: $10.3892 / \mathrm{mco} .2020 .2022$

\begin{abstract}
Radiotherapy techniques for breast cancer have evolved with efforts to reduce treatment-related side effects. In the present study, we conducted dosimetric analysis of incidental axillary irradiation between volumetric modulated arc therapy (VMAT) and three-dimensional conformal radiotherapy (3D-CRT). A total of 20 patients with early stage left breast cancer who underwent breast-conserving surgery followed by postoperative radiotherapy were analyzed. For VMAT plans, dose-volume constraints were not imposed on the axilla, as with 3D-CRT. We compared the dosimetric parameters of the planning target volumes, organs at risk and axillary level I-III of the two plans. VMAT showed better target coverage and a normal organ-sparing effect compared with 3D-CRT. The incidental axillary irradiation of VMAT was lower; the mean dose and the $\mathrm{V} \mathrm{O}_{\mathrm{Gy}}$ were significantly reduced at all axillary levels, with the exception of no difference in the maximum dose to axillary level I. In conclusion, VMAT decreased incidental axillary irradiation, even in the absence of a dose-volume constraint on the axilla, and can, therefore, decrease the risk of radiotherapy-related lymphedema. However, caution is also required because it is unclear whether this incidental axillary irradiation is beneficial for reducing recurrence on the axilla.
\end{abstract}

\section{Introduction}

Breast cancer treatment has gradually evolved to reduce side effects without compromising treatment outcomes $(1,2)$. Treatment-related side effects negatively affect quality of life,

Correspondence to: Dr Seung-Gu Yeo, Department of Radiation Oncology, Soonchunhyang University Hospital, 31 Sooncheonhyang 6-gil, Cheonan, Chungnam 31151, Republic of Korea

E-mail: md6630@schmc.ac.kr

Key words: axillary irradiation, incidental irradiation, breast cancer, radiotherapy, dosimetry, lymphedema delay treatment, and compromise results. The typical side effects include cardiac toxicity, dermatitis, and lymphedema by multimodal treatments using surgery, adjuvant chemotherapy and radiotherapy (RT) (3-7). Among them, the incidence of breast cancer-related lymphedema (BCRL) after treatment ranges from 14 to $40 \%$ (8), caused principally by axillary lymph node dissection (ALND) and adjuvant RT, particularly irradiation of the axillary level I and II (8-10). Sentinel lymph node biopsy has thus become standard treatment for clinically node-negative patients and has become an alternative for complete ALND. RT has also evolved from application of three-dimensional conformal RT (3D-CRT) to intensity-modulated RT (IMRT) or volumetric modulated arc therapy (VMAT) to achieve better conformity with the treatment target and reduce unnecessary irradiation of normal organs (11-22). VMAT has the potential for reduced treatment time compared with IMRT and the clinical use of VMAT is increasing gradually (23). When planning VMAT, dose-volume constraints should be applied to reduce or minimize irradiation of normal tissue. If axillary constraints are imposed in VMAT plan, the axillary dose can be less than that of 3D-CRT. However, it is unclear whether incidental axillary irradiation differs in VMAT without axillary constraint, as with 3D-CRT. In the present study, we investigated the difference in incidental irradiation dose on the axilla and dosimetric characteristics between the two aforementioned plans.

\section{Materials and methods}

Ethics approval. This study was approved by The Institutional Review Board of Soonchunhyang University Cheonan Hospital (approval no. SCHCA 2019-11-015-001) (Chungnam, Republic of Korea). Due to the retrospective nature, the requirement to obtain informed consent of the patients was waived by the board. All the procedures in this study were in accordance with the Declaration of Helsinki. Patients who participated in this research had complete clinical data. The signed informed consents were obtained from the patients or the guardians.

Stimulation of radiotherapy. We investigated 20 patients with left breast cancer who received breast-conserving 
surgery followed by postoperative RT in 2015 and 2016 . Eighteen patients $(90 \%)$ were $\mathrm{T} 1$ stage and two patients (10\%) were Tis stage. There were no axillary metastases in all patients. All patients underwent a free-breathing simulation computed tomography scan using the Philips Brilliance Big Bore (Philips Medical Systems) with $3 \mathrm{~mm}$ slice thickness. The patients lay supine on a no-tilting breast board (CIVCO Medical Solutions) without tilting angle, with the arms above the head for appropriate exposure of their breasts and axillae.

Contouring and planning. The clinical target volumes (CTVs) and axillary level I-III were delineated on the basis of the Radiation Therapy Oncology Group contouring guidelines for breast cancer (24). The superior CTV border was the sternal notch or $1 \mathrm{~cm}$ above the breast tissue, and the inferior border was $2 \mathrm{~cm}$ below the inframammary fold. The medial CTV border was the mid-sternum line and the lateral border was the mid-axillary line or a line $2 \mathrm{~cm}$ lateral to breast tissue. To generate the planning target volume (PTV), the CTV was expanded by $1 \mathrm{~cm}$ in all directions, and then $3 \mathrm{~mm}$ of skin was trimmed from the anterior border of the body surface. Axillary levels I-III were contoured separately, based on the positions of the pectoralis major, pectoralis minor, and intercostal muscles as well as the ribs. The organs at risk (OARs) included the ipsilateral and contralateral lung, heart, and spinal cord. All VMAT and 3D-CRT plans were performed using a radiation treatment planning system (Eclipse ver. 8.9; Varian Medical Systems Inc.) and 6-MV photon. Each 3D-CRT plan consisted of four portals with two optimal tangential angles. The physical wedges in the $\mathrm{x}$ - and $\mathrm{y}$-axis were applied once at each portal to improve the dose distribution. Each VMAT plan was performed using the same algorithm with the same energy as for 3D-CRT. The beam arrangement was optimized between 290 and 180 to conform maximally to individual PTVs and afford the OARs the best possible preservation. A ring structure around the PTV was created to obtain the appropriate treatment target conformity. During optimization of VMAT plan, the normal tissue objective was conducted dose-volume constraints for the heart and ipsilateral lung, but not the axilla to set similar conditions between 3D-CRT and VMAT. The prescription dose was 50 Gy in 25 fractions, and the plans were normalized such that $\geq 95 \%$ of the PTV received $100 \%$ of the prescription dose.

Statistical analysis. We recorded all doses to the PTVs, OARs and axillary level I-III. Additionally, the integral dose (ID) was reconstructed. The ID was calculated using the simplified formula ID $=\mathrm{V}_{\text {body }}$ (liters) $\mathrm{x}_{\text {mean in body, outside PTV }}(\mathrm{Gy})$ (25). Plan data were analyzed using the Mann-Whitney test with the SPSS 18.0 (SPSS, Inc.). P<0.05 was considered to indicate a statistically significant difference.

\section{Results}

Patient characteristics. The median age of the patients was 47 years (range: $36-66$ years). Invasive ductal carcinoma was confirmed in 17 patients $(85.0 \%)$. Table I shows the patient characteristics.
Table I. Patient characteristics.

\begin{tabular}{lc}
\hline Characteristics & Values $^{\mathrm{a}}$ \\
\hline Age, year & $47(36-66)$ \\
T stage & \\
Tis & $2(10.0)$ \\
T1 & $18(90.0)$ \\
Pathology & \\
DCIS & $17(10.0)$ \\
IDC & $1(5.0)$ \\
ILC & \\
Volumes of structures & \\
Body & $50.0(13,984.4-27,079.2)$ \\
PTV & $646.3(102.9-1,174.6)$ \\
Heart & $605.9(516.0-968.7)$ \\
Spinal cord & $(36.9-66.9)$ \\
Ipsilateral lung & $(627.3-1,324.5)$ \\
Total lung & $2,162.3(1,573.9-2,996.6)$ \\
Axilla & $63.6(35.7-106.0)$ \\
Level I & $20.7(13.3-41.8)$ \\
Level II & $13.5(9.3-24.3)$ \\
Level III &
\end{tabular}

${ }^{\text {a }}$ Values are presented as median (range) or number (\%). DCIS, ductal carcinoma in situ; IDC, invasive ductal carcinoma; ILC, invasive lobular carcinoma; PTV, planning target volume.

Doses of PTV and OARs. VMAT afforded $\geq 90 \%$ PTV coverage more reliably than did 3D-CRT. The V45 $5_{\mathrm{Gy}}$ of VMAT was $99.7 \pm 0.2 \%$, vs. $99.2 \pm 0.9 \%$ for $3 \mathrm{D}-\mathrm{CRT}(\mathrm{P}=0.002)$. However, the mean PTV dose did not differ between the two plans. Fig. 1 shows a representative image of both plans with the PTV and isodose lines.

Table II lists the OAR and ID data of the two plans and Fig. 2 shows the cumulative dose-volume histograms. In brief, moderate-to-high doses $\left(\mathrm{V} 25_{\mathrm{Gy}}\right.$ and $\mathrm{V} 40_{\mathrm{Gy}}$ ) of VMAT were lower than the 3D-CRT doses in all OARs. For the heart, VMAT was significantly lower than 3D-CRT (V25 $5_{\mathrm{Gy}}, 6.3 \%$ vs. $14.8 \%$; $\mathrm{V} 40_{\mathrm{Gy}}, 1.8 \%$ vs. $12.1 \%$, respectively, $\mathrm{P}<0.001$ ). For the ipsilateral lung, the moderate-to-high VMAT doses were lower than those for 3D-CRT (V25, $10.9 \%$ vs. $21.3 \%$; V40 $3.4 \%$ vs. $16.2 \%$, respectively, $\mathrm{P}<0.001)$. However, $\mathrm{V} 5_{\mathrm{Gy}}$ was higher for VMAT than 3D-CRT. For the heart, the $\mathrm{V} 5_{\mathrm{Gy}}$ for VMAT was higher than that for 3D-CRT (69.9\% vs. $27.1 \%$, respectively, $\mathrm{P}<0.001)$. For the ipsilateral lung, the $\mathrm{V} 5_{\mathrm{Gy}}$ for VMAT was higher than that for 3D-CRT $(74.5 \%$ vs. $39.1 \%$, respectively, $\mathrm{P}<0.001)$. The mean dose to the ipsilateral lung and spinal cord was higher for VMAT than $3 \mathrm{D}-\mathrm{CRT}(\mathrm{P}<0.001)$, while for the heart there was no difference between the two plans ( 9.5 Gy vs. $9.3 \mathrm{~Gy}$, respectively). Lastly, the ID to the body was higher for VMAT than 3D-CRT $(82.7 \mathrm{~Gy} \cdot \mathrm{L}$ vs. $64.6 \mathrm{~Gy} \cdot \mathrm{L}$, respectively, $\mathrm{P}<0.001)$.

Comparison of axillary doses. The doses to axillary levels I-III were analyzed separately. The mean, maximum, V25 $\mathrm{Gy}$ and 


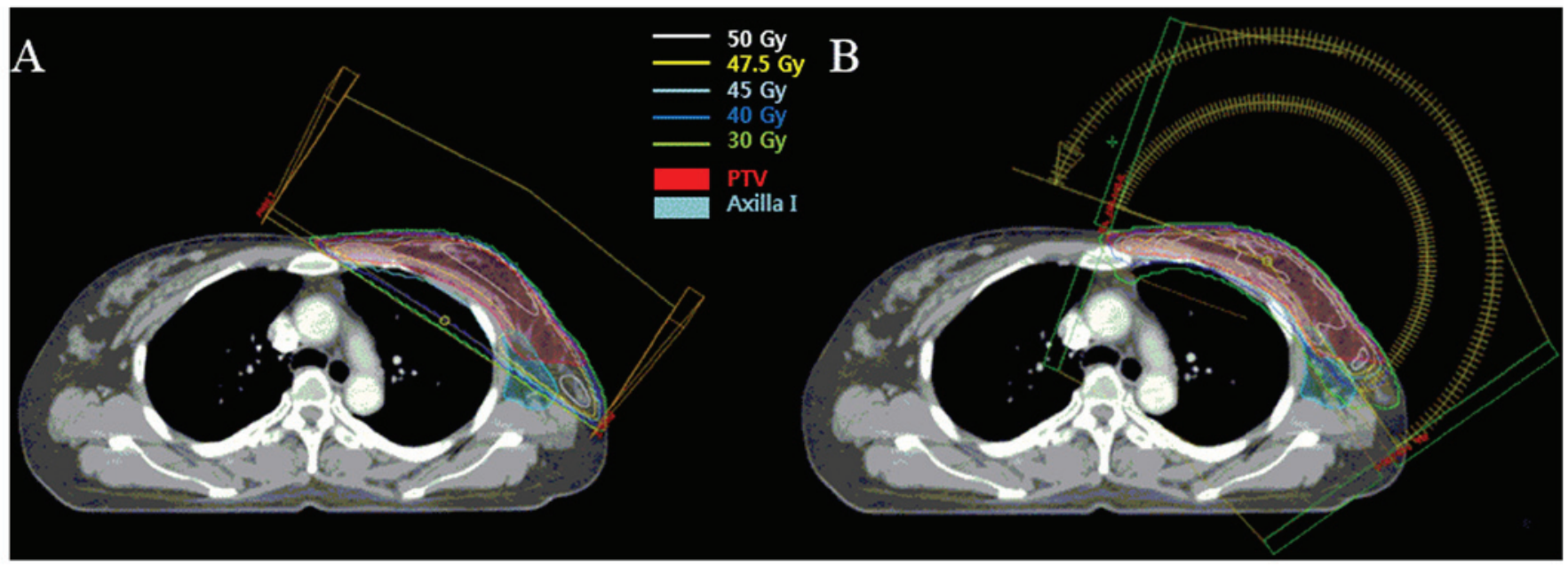

Figure 1. Typical radiotherapy plans of three-dimensional conformal radiotherapy and volumetric modulated arc therapy. (A) Each of two tangent angles used two portals with physical wedges in the x- and y-axis. (B) Two arcs, clockwise and counterclockwise, were from 290 to $145^{\circ}$. PTV is indicated by the red translucent area; axilla level I is indicated by the dark green translucent area; the white line indicates $50 \mathrm{~Gy}$; the yellow line indicates $47.5 \mathrm{~Gy}$; the cyan line indicates $45 \mathrm{~Gy}$; the blue line indicates $40 \mathrm{~Gy}$; the green line indicates $30 \mathrm{~Gy}$. PTV, planning target volume.

Table II. Dosimetric comparison of radiation dose delivered to PTV, organs at risk and integral dose between 3D-CRT and VMAT plans.

\begin{tabular}{|c|c|c|c|c|}
\hline Structure & Parameters & 3D-CRT & VMAT & P-value \\
\hline \multirow[t]{3}{*}{ PTV } & $\mathrm{D}_{\text {Mean }}(\mathrm{Gy})$ & $49.8 \pm 0.2$ & $49.8 \pm 0.0$ & 0.709 \\
\hline & $\mathrm{V} 45_{\mathrm{Gy}}(\%)$ & $99.2 \pm 0.9$ & $99.7 \pm 0.2$ & 0.002 \\
\hline & $\mathrm{V} 47.5_{\mathrm{Gy}}(\%)$ & $90.4 \pm 2.5$ & $93.1 \pm 1.7$ & 0.001 \\
\hline \multirow[t]{4}{*}{ Heart } & $\mathrm{D}_{\text {Mean }}(\mathrm{Gy})$ & $9.5 \pm 0.8$ & $9.3 \pm 1.8$ & 0.575 \\
\hline & $\mathrm{V} 5_{\mathrm{Gy}}(\%)$ & $27.1 \pm 8.9$ & $69.9 \pm 14.4$ & $<0.001$ \\
\hline & $\mathrm{V} 25_{\mathrm{Gy}}(\%)$ & $14.8 \pm 5.4$ & $6.3 \pm 2.8$ & $<0.001$ \\
\hline & $\mathrm{V} 40_{\mathrm{Gy}}(\%)$ & $12.1 \pm 5.0$ & $1.8 \pm 1.4$ & $<0.001$ \\
\hline \multirow[t]{4}{*}{ Ipsilateral lung } & $\mathrm{D}_{\text {Mean }}(\mathrm{Gy})$ & $12.4 \pm 2.1$ & $10.9 \pm 1.5$ & 0.001 \\
\hline & $\mathrm{V} 5_{\mathrm{Gy}}(\%)$ & $39.1 \pm 5.3$ & $74.5 \pm 10.7$ & $<0.001$ \\
\hline & $\mathrm{V} 25_{\mathrm{Gy}}(\%)$ & $21.3 \pm 4.3$ & $10.9 \pm 3.0$ & $<0.001$ \\
\hline & $\mathrm{V} 40_{\mathrm{Gy}}(\%)$ & $16.2 \pm 4.5$ & $3.4 \pm 1.8$ & $<0.001$ \\
\hline \multirow[t]{4}{*}{ Total lung } & $\mathrm{D}_{\text {Mean }}(\mathrm{Gy})$ & $5.9 \pm 1.1$ & $7.1 \pm 1.0$ & $<0.001$ \\
\hline & $\mathrm{V} 5_{\mathrm{Gy}}(\%)$ & $16.9 \pm 2.9$ & $48.8 \pm 9.4$ & $<0.001$ \\
\hline & $\mathrm{V} 25_{\mathrm{Gy}}(\%)$ & $9.2 \pm 2.2$ & $4.7 \pm 1.4$ & $<0.001$ \\
\hline & $\mathrm{V} 40_{\mathrm{Gy}}(\%)$ & $7.0 \pm 2.2$ & $1.5 \pm 0.8$ & $<0.001$ \\
\hline \multirow[t]{4}{*}{ Spinal cord } & $\mathrm{D}_{\text {Mean }}(\mathrm{Gy})$ & $0.7 \pm 0.2$ & $1.7 \pm 0.5$ & $<0.001$ \\
\hline & $\mathrm{V} 5_{\mathrm{Gy}}(\%)$ & $0.0 \pm 0.0$ & $0.1 \pm 0.1$ & 0.001 \\
\hline & $\mathrm{V} 25_{\mathrm{Gy}}(\%)$ & $0.0 \pm 0.0$ & $0.0 \pm 0.0$ & - \\
\hline & $\mathrm{V} 40_{\mathrm{Gy}}(\%)$ & $0.0 \pm 0.0$ & $0.0 \pm 0.0$ & - \\
\hline Body & ID $(\mathrm{Gy} \cdot \mathrm{L})$ & $64.6 \pm 17.7$ & $82.7 \pm 20.3$ & $<0.001$ \\
\hline
\end{tabular}

Data are presented as the mean \pm SD. 3D-CRT, three-dimensional-conformal radiotherapy; $\mathrm{D}_{\text {mean }}$, mean dose; PTV, planning target volume; VMAT, volumetric modulated arc therapy; Vn, percentage of volume receiving at least $\mathrm{n} \mathrm{Gy}$.

$\mathrm{V} 40_{\text {Gy }}$ are shown in Table III and Fig. 3. The mean doses to each axillary level were significantly lower for VMAT vs.
Table III. Dosimetric comparison of radiation dose delivered to axilla level I-III between 3D-CRT and VMAT.

\begin{tabular}{|c|c|c|c|c|}
\hline Structure & Parameters & 3D-CRT & VMAT & P-value \\
\hline \multirow[t]{4}{*}{ Level I } & $\mathrm{D}_{\text {Mean }}(\mathrm{Gy})$ & $39.5 \pm 4.7$ & $36.8 \pm 6.4$ & 0.010 \\
\hline & $\mathrm{D}_{\text {Max }}(\mathrm{Gy})$ & $49.3 \pm 7.2$ & $52.4 \pm 0.8$ & $<0.001$ \\
\hline & $\mathrm{V} 25_{\mathrm{Gy}}(\%)$ & $83.2 \pm 12.2$ & $80.0 \pm 17.2$ & 0.313 \\
\hline & $\mathrm{V} 40_{\mathrm{Gy}}(\%)$ & $74.3 \pm 15.1$ & $54.3 \pm 16.1$ & $<0.001$ \\
\hline \multirow[t]{4}{*}{ Level II } & $\mathrm{D}_{\text {Mean }}(\mathrm{Gy})$ & $18.0 \pm 12.4$ & $14.2 \pm 11.3$ & $<0.001$ \\
\hline & $\mathrm{D}_{\text {Max }}(\mathrm{Gy})$ & $37.4 \pm 11.7$ & $33.5 \pm 18.9$ & 0.391 \\
\hline & $\mathrm{V} 25_{\mathrm{Gy}}(\%)$ & $32.6 \pm 32.1$ & $24.0 \pm 30.3$ & 0.001 \\
\hline & $\mathrm{V} 40_{\mathrm{Gy}}(\%)$ & $19.8 \pm 26.9$ & $6.5 \pm 11.8$ & 0.002 \\
\hline \multirow[t]{4}{*}{ Level III } & $\mathrm{D}_{\text {Mean }}(\mathrm{Gy})$ & $8.0 \pm 8.7$ & $6.3 \pm 6.5$ & 0.025 \\
\hline & $\mathrm{D}_{\text {Max }}(\mathrm{Gy})$ & $24.0 \pm 18.2$ & $19.1 \pm 17.1$ & 0.003 \\
\hline & $\mathrm{V} 25_{\mathrm{Gy}}(\%)$ & $11.7 \pm 20.6$ & $5.1 \pm 11.9$ & 0.005 \\
\hline & $\mathrm{V} 40_{\mathrm{Gy}}(\%)$ & $5.2 \pm 11.2$ & $0.6 \pm 2.2$ & 0.018 \\
\hline
\end{tabular}

Data are presented as the mean $\pm \mathrm{SD}$. 3D-CRT, three-dimensional-conformal radiotherapy; $\mathrm{D}_{\max }$, maximum dose; $\mathrm{D}_{\text {mean, }}$ mean dose; VMAT, volumetric modulated arc therapy; Vn percentage of volume receiving at least $\mathrm{n}$ Gy.

3D-CRT. The $\mathrm{V} 25_{\mathrm{Gy}}$ and $\mathrm{V} 40_{\mathrm{Gy}}$ for VMAT were significantly lower than those for 3D-CRT, except the $\mathrm{V} 25_{\mathrm{Gy}}$ of axillary level I. The max VMAT doses to axillary levels II and III were lower than those for 3D-CRT, while that to axillary level I was not.

Thus, target conformity was better for VMAT than the 3D-CRT; the incidental axillary dose with VMAT was lower than that with 3D-CRT, despite non-imposition of an axillary dose-volume constraint. The moderate-to-high doses delivered to the OARs were lower with VMAT than 3D-CRT, while the low dose and ID to the body were higher with VMAT than 3D-CRT. 

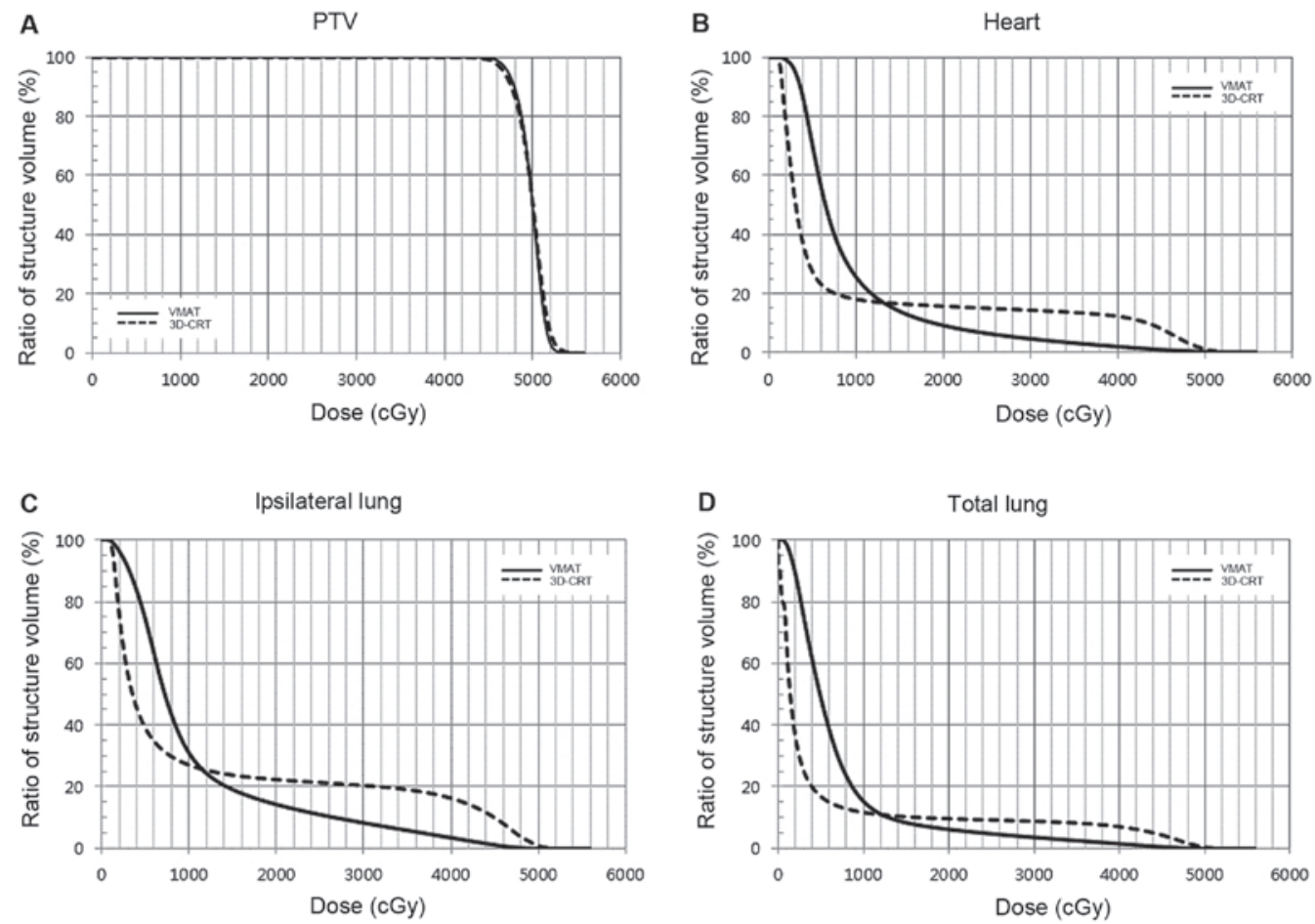

Figure 2. Cumulative dose-volume histogram of (A) PTV and organs at risk, including (B) heart, (C) ipsilateral heart and (D) total lung between 3D-CRT (dashed line) and VMAT (solid line) in all patients. PTV, planning target volume; 3D-CRT, three-dimensional conformal radiotherapy; VMAT, volumetric modulated arc therapy.
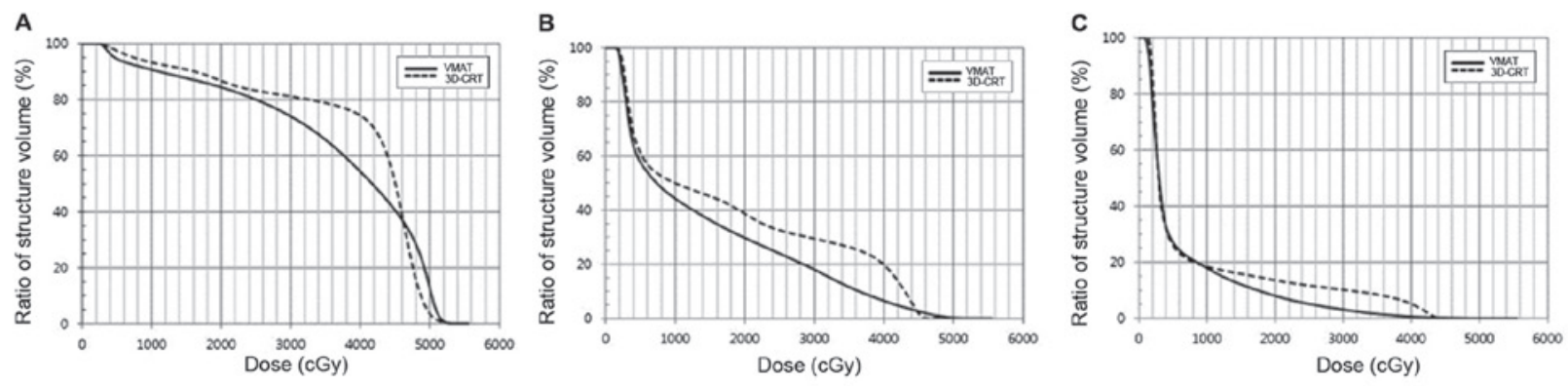

Figure 3. Cumulative dose-volume histogram of axilla (A) level I, (B) level II and (C) level III between 3D-CRT (dashed line) and VMAT (solid line) in all patients. 3D-CRT, three-dimensional conformal radiotherapy; VMAT, volumetric modulated arc therapy.

\section{Discussion}

Radiation-related side effects in breast cancer patients vary. One of the most common is ipsilateral arm edema (3-7). In the After Mapping of the Axilla: Radiotherapy Or Surgery (AMAROS) study, 15\% of patients showed clinical signs of lymphedema 1 year after axillary RT without ALND, 14\% at 3 years, and $11 \%$ at 5 years (6). Interruption of the axillary lymphatic system due to breast cancer treatment results in BCRL, which has a negative effect on quality of life in breast cancer patient (26-28).

We did not impose a dose-volume constraint on the axilla to ensure similar conditions between VMAT and 3D-CRT. Nevertheless, we found that VMAT significantly lowered the incidental axillary radiation dose and, at the same time, increased the target conformity compared with 3D-CRT. During the VMAT optimization process, an option of normal tissue objective and the ring structure would also have been helpful to reduce axillary irradiation and improve target conformity $(29,30)$. The better conformity reduces unnecessary radiation doses to tissues other than targets, thereby effectively reducing RT-related side effects, including lymphedema $(31,32)$.

A few studies have reported on reducing incidental axillary irradiation in breast cancer patients using several RT techniques. According to Kataria et al, who did not impose a dose-volume constraint on the axilla, as in the present study, when comparing IMRT (two tangential semi-opposed beams with gantry angles of 130-145 and 305-320 for the medial and lateral fields, respectively) with 3D-CRT (tangential beams with the same angles and orientations as IMRT), the incidental axillary irradiation with IMRT was lower than with 3D-CRT at levels I and II (19). Zhang et al also imposed no constraint on the axilla and compared between conformal techniques such as simplified-IMRT (s-IMRT; five to seven beams) with forward IMRT (for-IMRT; two tangential 
opposite beams with the field-in-field technique) (33). The unintended dose to the axilla, especially level I, was lower with s-IMRT than for-IMRT. The mean $\mathrm{V} 40_{\mathrm{Gy}}, \mathrm{V} 45_{\mathrm{Gy}}$, and V47.5 $5_{\text {Gy }}$ of axillary levels II and III were very low in both conformal techniques, and the results were similar to the VMAT plans in the present study. Lee et al showed that IMRT (seven fields with a skin-sparing technique) delivered significantly less incidental axilla radiation than 3D-CRT (parallel-opposite tangential fields with the field-in-field technique), although they did not report whether axilla constraint was considered during IMRT (34). To our knowledge, some studies have compared incidental axillary irradiation with IMRT, but none discussed incidental axillary irradiation with VMAT. According to the aforementioned studies and the present study, even if there is no constraint on the axillary region, it is possible to reduce the incidentally irradiated dose to the axilla by using advanced RT techniques, especially with VMAT.

However, this incidental or unintended axillary irradiation may not always be harmful. Although it comes short of a therapeutic dose, incidental irradiation of the axilla from tangential fields may exert some effects on controlling axillary occult disease (35). Krasin et al stated that treatment with tangential fields using three-dimensional techniques still had a role in controlling subclinical disease of axilla, despite a significant incidental dose to the axilla (36). Fisher et al reported that in early breast cancer patients, the axillary recurrence rate following postoperative breast RT was $4.5 \%$ compared with $7.2 \%$ in the surgery alone group (37). Further studies are necessary to determine whether reducing incidental axillary irradiation with advanced RT techniques, including VMAT, will have a negative impact on regional axillary recurrence.

There is a concern that patients treated with the VMAT technique are exposed to a higher ID to the body, unwanted spinal cord irradiation and higher low-level doses to other OARs such as lung and heart, compared with 3D-CRT. Because patients with early-stage breast cancer have a relatively long life expectancy, the higher ID to the body and low-dose bath of normal organs has been criticized due to the potential risk of secondary cancer $(38,39)$. However, there is no evidence that this has a role in carcinogenesis (40), and even if secondary cancers develop from RT, the attributable mortality rate was estimated to be only 1 2\% after 10 years (41). Although malignant potential risks are suspected low, it should be noted that other clinical side effects such as symptomatic lung injury or cardiac events can be caused by low radiation doses $(42,43)$. Therefore, the risk should be balanced against the apparent benefits of decreasing the side effects.

In conclusion, this study showed that VMAT, even without dose-volume constraint on the axilla, significantly reduces incidental axillary irradiation compared with 3D-CRT. Clinical studies should be followed to prove that this dosimetric change with advanced RT techniques can reduce BCRL while maintaining efficacy in disease control.

\section{Acknowledgements}

Not applicable.

\section{Funding}

The present study was supported by The Soonchunhyang University Research Fund.

\section{Availability of data and materials}

The datasets used and/or analyzed during the present study are available from the corresponding author on reasonable request.

\section{Authors' contributions}

IYJ analyzed and interpreted patient data, and wrote the manuscript. ESK analyzed and interpreted data. WCK and CKM acquired and analyzed data. SGY designed the study and critically revised the manuscript. All authors read and approved the final manuscript.

\section{Ethics approval and consent to participate}

This study was approved by The Institutional Review Board of Soonchunhyang University Cheonan Hospital (approval no. SCHCA 2019-11-015-001) (Cheonan, Republic of Korea). Due to the retrospective nature, the requirement to obtain informed consent of the patients was waived by the board. All the procedures in this study were in accordance with the Declaration of Helsinki. Patients who participated in this research had complete clinical data. The signed informed consents were obtained from the patients or the guardians.

\section{Patient consent for publication}

Not applicable.

\section{Competing interests}

The authors declare that they have no competing interests.

\section{References}

1. Dominici LS, Morrow M, Mittendorf E, Bellon J and King TA: Trends and controversies in multidisciplinary care of the patient with breast cancer. Curr Probl Surg 53: 559-595, 2016.

2. Yeo SG, Kim J, Kwak GH, Kim JY, Park K, Kim ES and Han S: Accelerated partial breast irradiation using multicatheter brachytherapy for select early-stage breast cancer: Local control and toxicity. Radiat Oncol 5: 56, 2010.

3. Martel S, Maurer C, Lambertini M, Ponde N and De Azambuja E: Breast cancer treatment-induced cardiotoxicity. Expert Opin Drug Saf 16: 1021-1038, 2017.

4. Meattini I, Guenzi M, Fozza A, Vidali C, Rovea P, Meacci F and Livi L: Overview on cardiac, pulmonary and cutaneous toxicity in patients treated with adjuvant radiotherapy for breast cancer. Breast Cancer 24: 52-62, 2017.

5. Petersen $\mathrm{C}$ and Würschmidt F: Late toxicity of radiotherapy: A problem or a challenge for the radiation oncologist? Breast Care (Basel) 6: 369-374, 2011.

6. Donker M, van Tienhoven G, Straver ME, Meijnen P, van de Velde CJ, Mansel RE, Cataliotti L, Westenberg AH, Klinkenbijl JH, Orzalesi L, et al: Radiotherapy or surgery of the axilla after a positive sentinel node in breast cancer (EORTC 10981-22023 AMAROS): A randomised, multicentre, open-label, phase 3 non-inferiority trial. Lancet Oncol 15: 1303-1310, 2014. 
7. Warren LE, Miller CL, Horick N, Skolny MN, Jammallo LS, Sadek BT, Shenouda MN, O'Toole JA, MacDonald SM, Specht MC and Taghian AG: The impact of radiation therapy on the risk of lymphedema after treatment for breast cancer: A prospective cohort study. Int J Radiat Oncol Biol Phys 88: 565-571, 2014

8. Rockson SG: Lymphedema after breast cancer treatment. N Engl J Med 379: 1937-1944, 2018.

9. Kilbreath SL, Refshauge KM, Beith JM, Ward LC, Ung OA, Dylke ES, French JR, Yee J, Koelmeyer L and Gaitatzis K: Risk factors for lymphoedema in women with breast cancer: A large prospective cohort. Breast 28: 29-36, 2016.

10. Gross JP, Sachdev S, Helenowski IB, Lipps D, Hayes JP, Donnelly ED and Strauss JB: Radiation therapy field design and lymphedema risk after regional nodal irradiation for breast cancer. Int J Radiat Oncol Biol Phys 102: 71-78, 2018.

11. Gera R, Kasem A and Mokbel K: Can complete axillary node dissection be safely omitted in patients with early breast cancer when the sentinel node biopsy is positive for malignancy? An update for clinical practice. In Vivo 32: 1301-1307, 2018.

12. Kestin LL, Sharpe MB, Frazier RC, Vicini FA, Yan D, Matter RC, Martinez AA and Wong JW: Intensity modulation to improve dose uniformity with tangential breast radiotherapy: Initial clinical experience. Int J Radiat Oncol Biol Phys 48: 1559-1568, 2000.

13. Jo IY, Kim SW and Son SH: Dosimetric evaluation of the skin-sparing effects of 3-dimensional conformal radiotherapy and intensity-modulated radiotherapy for left breast cancer. Oncotarget 8: 3059-3063, 2017.

14. Mansouri S, Naim A, Glaria L and Marsiglia H: Dosimetric evaluation of 3-D conformal and intensity-modulated radiotherapy for breast cancer after conservative surgery. Asian Pac J Cancer Prev 15: 4727-4732, 2014.

15. Vugts G, Maaskant-Braat AJ, Voogd AC, van Riet YE, Luiten EJ, Rutgers EJ, Rutten HJ, Roumen RM and Nieuwenhuijzen GA: Repeat sentinel node biopsy should be considered in patients with locally recurrent breast cancer. Breast Cancer Res Treat 153: 549-556, 2015.

16. Giuliano AE, Ballman KV, McCall L, Beitsch PD, Brennan MB, Kelemen PR, Ollila DW, Hansen NM, Whitworth PW, Blumencranz PW, et al: Effect of axillary dissection vs no axillary dissection on 10-year overall survival among women with invasive breast cancer and sentinel node metastasis: The ACOSOG Z0011 (Alliance) randomized clinical trial JAMA 318: 918-926, 2017.

17. Galimberti V, Cole BF, Viale G, Veronesi P, Vicini E, Intra M, Mazzarol G, Massarut S, Zgajnar J, Taffurelli M, et al: Axillary dissection versus no axillary dissection in patients with breast cancer and sentinel-node micrometastases (IBCSG 23-01): 10-year follow-up of a randomised, controlled phase 3 trial. Lancet Oncol 19: 1385-1393, 2018

18. Dogan N, Cuttino L, Lloyd R, Bump EA and Arthur DW: Optimized dose coverage of regional lymph nodes in breast cancer: The role of intensity-modulated radiotherapy. Int J Radiat Oncol Biol Phys 68: 1238-1250, 2007.

19. Kataria T, Bisht SS, Gupta D, Goyal S, Jassal K, Abhishek A, Sharma K, Pareek P, Kumar V, Jain S, et al: Incidental radiation to axilla in early breast cancer treated with intensity modulated tangents and comparison with conventional and 3D conformal tangents. Breast 22: 1125-1129, 2013.

20. Henke G, Knauer M, Ribi K, Hayoz S, Gérard MA, Ruhstaller T, Zwahlen DR, Muenst S, Ackerknecht M, Hawle H, et al: Tailored axillary surgery with or without axillary lymph node dissection followed by radiotherapy in patients with clinically node-positive breast cancer (TAXIS): Study protocol for a multicenter, randomized phase-III trial. Trials 19: 667, 2018.

21. Rastogi K, Sharma S, Gupta S, Agarwal N, Bhaskar S and Jain S: Dosimetric comparison of IMRT versus 3DCRT for post-mastectomy chest wall irradiation. Radiat Oncol J 36: 71-78, 2018.

22. Balaji K, Subramanian B, Yadav P, Anu Radha C and Ramasubramanian V: Radiation therapy for breast cancer. Med Dosim 41: 253-257, 2016.

23. Teoh M, Clark CH, Wood K, Whitaker S and Nisbet A: Volumetric modulated arc therapy: A review of current literature and clinical use in practice. Br J Radiol 84: 967-996, 2011.

24. Gentile MS, Usman AA, Neuschler EI, Sathiaseelan V, Hayes JP and Small W Jr: Contouring guidelines for the axillary lymph nodes for the delivery of radiation therapy in breast cancer: Evaluation of the RTOG breast cancer atlas. Int J Radiat Oncol Biol Phys 93: 257-265, 2015.
25. Badakhshi H, Kaul D, Nadobny J, Wille B, Sehouli J and Budach V: Image-guided volumetric modulated arc therapy for breast cancer: A feasibility study and plan comparison with three-dimensional conformal and intensity-modulated radiotherapy. Br J Radiol 86: 20130515, 2013.

26. Penha TR, Botter B, Heuts EM, Voogd AC, von Meyenfeldt MF and van der Hulst RR: Quality of life in patients with breast cancer-related lymphedema and reconstructive breast surgery. J Reconstr Microsurg 32: 484-490, 2016.

27. Ganz PA: The quality of life after breast cancer-solving the problem of lymphedema. N Engl J Med 340: 383-385, 1999.

28. Cornelissen AJM, Kool M, Keuter XHA, Heuts EM, Piatkowski de Grzymala AA, van der Hulst RRWJ and Qiu SS: Quality of life questionnaires in breast cancer-related lymphedema patients: Review of the literature. Lymphat Res Biol 16: 134-139, 2018

29. Fadda G, Massazza G, Zucca S, Durzu S, Meleddu G, Possanzini M and Farace P: Quasi-VMAT in high-grade glioma radiation therapy. Strahlenther Onkol 189: 367-371, 2013.

30. Jolly D, Alahakone D and Meyer J: A rapidArc planning strategy for prostate with simultaneous integrated boost. J Appl Clin Med Phys 12: 3320, 2010.

31. Rudat V, Alaradi AA, Mohamed A, Ai-Yahya K and Altuwaijri S: Tangential beam IMRT versus tangential beam 3D-CRT of the chest wall in postmastectomy breast cancer patients: A dosimetric comparison. Radiat Oncol 6: 26, 2011

32. Xie X, Ouyang S, Wang H, Yang W, Jin H, Hu B and Shen L: Dosimetric comparison of left-sided whole breast irradiation with 3D-CRT, IP-IMRT and hybrid IMRT. Oncol Rep 31: 2195-2205, 2014

33. Zhang L, Yang ZZ, Chen XX, Tuan J, Ma JL, Mei X, Yu XL, Zhou ZR, Shao ZM, Liu GY and Guo XM: Dose coverage of axillary level I-III areas during whole breast irradiation with simplified intensity modulated radiation therapy in early stage breast cancer patients. Oncotarget 6: 18183-18191, 2015.

34. Lee J, Kim SW and Son SH: Dosimetric evaluation of incidental irradiation to the axilla during whole breast radiotherapy for patients with left-sided early breast cancer in the IMRT era. Medicine (Baltimore) 95: e4036, 2016.

35. Reed DR, Lindsley SK, Mann GN, Austin-Seymour M, Korssjoen T, Anderson BO and Moe R: Axillary lymph node dose with tangential breast irradiation. Int J Radiat Oncol Biol Phys 61: 358-364, 2005.

36. Krasin M, McCall A, King S, Olson M and Emami B: Evaluation of a standard breast tangent technique: A dose-volume analysis of tangential irradiation using three-dimensional tools. Int $\mathbf{J}$ Radiat Oncol Biol Phys 47: 327-333, 2000.

37. Fisher B, Redmond C, Poisson R, Margolese R, Wolmark N, Wickerham L, Fisher E, Deutsch M, Caplan R, Pilch Y, et al: Eight-year results of a randomized clinical trial comparing total mastectomy and lumpectomy with or without irradiation in the treatment of breast cancer. N Engl J Med 320: 822-828, 1989.

38. Hall EJ and Wuu CS: Radiation-induced second cancers: The impact of 3D-CRT and IMRT. Int J Radiat Oncol Biol Phys 56: 83-88, 2003.

39. Han EY, Paudel N, Sung J, Yoon M, Chung WK and Kim DW: Estimation of the risk of secondary malignancy arising from whole-breast irradiation: Comparison of five radiotherapy modalities, including TomoHDA. Oncotarget 7: 22960-22969, 2016.

40. Alongi F, Giaj-Levra N, Fiorentino A, Mazzola R, Fersino S, Ricchetti F and Ruggieri R: Low-dose bath with volumetric modulated arc therapy in breast cancer: 'Much ado about nothing?'. Tumori 102: 335-336, 2016.

41. Darby SC, McGale P, Taylor CW and Peto R: Long-term mortality from heart disease and lung cancer after radiotherapy for early breast cancer: Prospective cohort study of about 300,000 women in US SEER cancer registries. Lancet Oncol 6: 557-565, 2005.

42. Chen J, Hong J, Zou X, Lv W, Guo F, Hong H and Zhang W: Association between absolute volumes of lung spared from low-dose irradiation and radiation-induced lung injury after intensity-modulated radiotherapy in lung cancer: A retrospective analysis. J Radiat Res 56: 883-888, 2015.

43. Ni L, Koshy M, Connell P, Pitroda S, Golden DW, Al-Hallaq H, Hubert G, Kauffman G, McCall A and Malik R: Heart V5 predicts cardiac events in unresectable lung cancer patients undergoing chemoradiation. J Thorac Dis 11: 2229-2239, 2019. 